\title{
After Toronto
}

\section{Effective AIDS prevention requires far better understanding of why existing strategies do not succeed.}

$\Lambda$ $t$ the AIDS meeting that has just ended in Toronto, the resounding theme was a fresh emphasis on prevention of the disease. The reasons for this are straightforward. A lot of work has been done to get antiretroviral therapies out to 1.3 million people with HIV, but that is still only one-fifth of the people who need them. And for every person put on life-saving treatments each year, there are ten new infections.

Some promising prevention strategies are edging from the laboratory to the clinic. Trials on microbicides, which could help protect women whose partners won't use a condom, are expected to start delivering results late next year. One large trial has already found that male circumcision may cut the risk of HIV infection by $60 \%$, and others are attempting to confirm this finding. Another study has established that antiretroviral drugs are safe for daily dosing in people without HIV, paving the way for larger tests of whether this could protect people from infection. All these approaches have limitations but are worthy of fuller exploration.

Additionally, an emerging move towards large-scale collaboration could bolster the efficiency of HIV research. Microbicide researchers are already communicating dosely through several formal and informal mechanisms, and a roadmap was set out for this in a Microbicide Development Strategy, released on 17 August.

Vaccine researchers have also recently been required to collaborate more closely, under the umbrella of the Global HIV Vaccine Enterprise, supported by the Bill \& Melinda Gates Foundation. Such collaboration has unfortunately been rare since the early days of HIV vaccine research. It may help to tackle some of the frustrations and dead-ends that have characterized the field from the start.

Individual HIV researchers have also begun banding together to counter divisive tendencies that they say have held the field back. Bruce Walker of Harvard Medical School has announced the beginning of a study on people who maintain good health despite being infected with HIV (see page 852). By studying these 'élite controllers',

Walker and his colleagues aim to discover why these patients are able to conquer the virus, whereas others cannot. That information could guide a more effective vaccine. Walker says the study will publish its results under a groupname - the HIV Elite Controllers Consortium with no first or senior author. This is a conscious attempt to break away from the divisions and rivalries that have previously dogged some research teams.

The approach is encouraging. But one of the most quoted statistics at the AIDS meeting was that one in five people worldwide at high risk of HIV infection don't have access to prevention practices that already exist. This is partly a resource problem: according to Beatrice Were of ActionAid Uganda, there are only three condoms per year available for every man in southern Africa.

But the failure of prevention strategies is also a scientific problem. On 17 August, a team from the World Health Organization and Johns Hopkins Bloomberg School of Public Health in Baltimore, Maryland, described their efforts to survey the published literature to establish what works for AIDS prevention in poor countries. The interventions studied induded harm-reduction strategies for drug users who inject, targeted educa-

"One in five people worldwide at high risk of HIV infection don't have access to prevention practices that already exist." tion programmes and abstinence. The meta-analysis found compelling evidence only for harm reduction - the strategy that political leaders, particularly in the United States, are least willing to fund.

The survey's main conclusion was that there remains a paucity of reliable data on the effectiveness of prevention strategies in developing countries. More epidemiologists and social scientists need to focus their energies on testing appropriate prevention methods in the places where the AIDS epidemic is at its worst. It is hopeless to await success with microbicides, or other biomedical strategies, if we don't even know why current interventions are failing.

\section{State of readiness}

\section{The anniversary of Hurricane Katrina should remind scientists to keep disaster recovery plans in order.}

\lceil his week marks the first anniversary of Hurricane Katrina's devastating visit to the US Gulf Coast. The images associated with the disaster are well-known: the anguish of New Orleans residents trapped at the Superdome as rescue teams rafted from house to house, finding mainly corpses.

But researchers would do well to recall a Katrina image of their own: that of a convoy of sports utility vehicles, escorted by armed guards, that descended on university buildings after the disaster.
Emergency workers were able to salvage some important biomedical data, retrieving important laboratory animals and thrusting cell cultures and tissue specimens into temporary refrigeration.

At several institutions in the city, however, including the healthsciences centre at Tulane University (see page 856), key research materials were lost. What wasn't flooded by Katrina's waters was doomed by power failures in the stifling August heat. Back-up generators, where they existed, were often in flood-prone basements.

The pattern of loss echoed an experience in Houston, Texas, in 2001, when Tropical Storm Allison swept ashore, flooding lowlying buildings. Dozens of monkeys and dogs were drowned at the University of Texas Medical Center at Houston. Last year, a similar fate befell 8,000 laboratory animals at the Louisiana State University Medical Center in New Orleans. Many drowned in the floodwaters; 
others starved or had to be killed later. Unfortunately, the obvious lessons from Allison had not been applied in New Orleans in time for Katrina.

Relatively simple precautions can often prepare laboratories to deal with natural disasters, especially in regions where the risk is known to be high. In earthquake-prone San Francisco, researchers typically know how well their buildings are constructed to withstand a quake, and sometimes practise procedures for evacuation in such an event. In New Orleans, researchers had lived with the threat of flooding for years. Yet the threat was perceived as indeterminate - everything, it seemed, would be fine, except in the event of a levee breaking. Of course, the levee broke.

Subsequent events should remind scientists in regions where such risks exist to revisit their own laboratories' emergency preparations. Researchers who work with animals should prepare a tagging system to help them identify the animals most crucial to their work. In the case of power outages, rescuers can identify those animals through their brightly coloured tags and know to take them out first.

Those with crucial cell lines in need of refrigeration should make sure that back-up systems are in place to keep the samples cold. Dry-ice can serve to keep precious samples refrigerated, even if the power is out for several days.

For most organizations, maintaining communications will be the most critical aspect of disaster recovery. Laboratories should ensure they have up-to-date telephone numbers for all members of the lab, and a system in place for who should contact whom in an emergency. E-mail systems should be backed up on remote servers, so they can be kept running throughout. These steps assume, of course, that some infrastructure will continue to function within a nearby community, where evacuees can regroup.

Such preparations rarely take priority until disaster strikes. But every researcher, from lab head to summer student, should look at what surrounds them, apply some common sense, and acquaint themselves with the basics of disaster recovery for their laboratory.

\section{Foo's paradise}

\section{In praise of chat.}

I's not uncommon to hear despairing complaints about some highpowered meeting that it was 'nothing more than a talking shop'. If one is going to all the trouble of gathering these people, the accusation suggests, it should deliver something.

That's a fair complaint when hard-edged achievement is the avowed intention. But maybe too little credence is given to gatherings that are expressly intended to foster conversation, organized in the enlightened hope that people will be stimulated and that unanticipated developments will follow. The duty of the organizers, then, is simply to maximize the chances of positive encounters.

Some years ago, the publisher Tim O'Reilly and his colleagues conceived the idea of just such a talkfest. O'Reilly is an influential enthusiast of participative web activities such as wikis and blogs. And in the same spirit, the programme of such meetings is developed on the spot by the 100-odd participants, who arrive at some enjoyable location and camp together for three days. The initial idea was to invite friends of O'Reilly', and thus was the first 'Foo camp' conceived. True to form, no grand manifestos or initiatives have emerged, but there has been plenty of stimulation and, no doubt, some upward blips in the revenues of manufacturers of alcoholic beverages.

Given the interest of Nature and its publishers in participatory publishing - see, for example, the strings of comments on some of the news stories of news@nature.com and our trial of open peer review (http://blogs.nature.com/nature/peerreview/trial/) - it was no surprise that we should fraternize with $O$ 'Reilly and conceive the idea of a science Foo. And it was gratifying that Google thought the idea sufficiently fun to be worth hosting such a get-together. And so it was that 200 people - scientists, mainly, infused with technologists and writers - turned up at the 'Googleplex' in Mountain View, California, earlier this month, for a long weekend of chat.

Invitees, who ranged across disciplines, age and nationality, were not told who else was coming. They were simply invited to get themselves there. Formal presentations were not encouraged. And the key to the dynamic was the programme: a wall chart with an empty matrix of one-hour sessions in a number of variously sized rooms stretching across two-and-a-half days, each session to be specified by any individual attendee as the meeting progressed. (It was fun to see who rated their session as worthy of 150 people's attention, and who offered their topic to a mere eight.)

After an introductory session, the participants developed a programme of titles such as 'how to radicalize scientists', 'open peer review and science wikis', 'the future of human evolution', 'text mining,' 'educational robotics', 'global health', 'the semantic web and the life sciences', and 'citizen scientists' (which features in this week's Nature podcast).

Inevitably such meetings will pick up on common concerns of the moment - such as the relationship between science and politics, how scientists should deal with fallacious media coverage, the balance between open and proprietary approaches to anything and everything. But there were plenty of uncommon ideas too, such as putting an atmospheric sensor on every mobile phone, and analysing the 'parameter space' of sciences and technologies in order to map and anticipate future advances.

The exercise could be portrayed by "Many attendees commented on the stimulation of getting feedback on their ideas from an unusual mix of expertise." cost-conscious administrators as a colossal act of self-indulgence. But, for example, an entrepreneur who wants to design a $\$ 20$ float for an oceanography experiment got some ideas about how to move his project forward, and an advocate of public participation in clinical trials was given feedback on her plans to use home DNA kits to boost involvement in a cancer trial. Many attendees commented on the stimulation of getting feedback on their ideas from an unusual mix of expertise.

But above all, it was the mode of spontaneous organization that gave the meeting a drive that is unusual and worth promoting. If this is what a talking-shop can be like, let's have more of them. 